\title{
Not All Pain is Created Equal: Basic Definitions and Diagnostic Work-Up
}

Cesare Bonezzi (1) - Diego Fornasari - Claudio Cricelli •

Alberto Magni · Giuseppe Ventriglia

Received: July 27, 2020 / Accepted: November 4, 2020 / Published online: December 11, 2020

(C) The Author(s) 2020

\section{ABSTRACT}

Chronic pain is considered a public health priority by the World Health Organization and European health institutions. It has reached alarming proportions in terms of disability, consumption of health and social resources, and impact on primary and specialist care services. Primary care physicians are often called on to manage this condition. Chronic pain management can be challenging due to its complexity. It has traditionally been considered to include nociceptive pain that that persists longer than the normal healing time, neuropathic pain lasting more than 3 months, or a combination of these. More recently, a third descriptor, nociplastic (primary) pain, was added to classify patients with chronic pain

C. Bonezzi $(\bowtie)$

ICS Maugeri IRCCS, Via Salvatore Maugeri 10, Pavia, Italy

e-mail: cesare.bonezzi@icsmaugeri.it

D. Fornasari

Department of Medical Biotechnology and

Translational Medicine, Università degli Studi di

Milano, Via Vanvitelli 32, Milan, Italy

C. Cricelli · A. Magni · G. Ventriglia

SIMG (Italian College of General Practitioners and Primary Care), Via Del Sansovino 179, Florence, Italy conditions such as fibromyalgia, nonspecific back pain, or mixed pain that persists or other conditions in which altered central pain modulation results in central sensitization and chronic pain in the absence of actual or threatened damage to tissues, including in the somatosensory nervous system. This document provides an overview of pain types and their underlying mechanisms. Successful pain management is facilitated by identification of the pain type. A set of diagnostic tools and a pain algorithm are presented to guide the clinician toward the correct diagnosis. The algorithm identifies cases that may require referral to a pain specialist. Once the site of origin of the pain (the "pain generator") is identified, or a primary pain syndrome is suspected, the accompanying article provides information and rationale to support treatment decisions based on patient characteristics.

Keywords: Chronic pain; Diagnosis; Primary care 


\section{Key Summary Points}

Chronic pain is prevalent and burdensome.

This publication reviews the basic mechanisms underlying chronic pain and presents a pathway for identifying the points where painful impulses are generated or modified, the so-called "pain generators".

We propose the SIMG 3.0 approach from the Italian Society of General Medicine to decrease misdiagnosis and promote the appropriate management of patients with chronic pain.

The accompanying article covers pharmacological treatment for patients with chronic non-cancer pain, based on the underlying pain generator and patient characteristics.

Patients with refractory chronic pain, especially pain with neuropathic or nociplastic characteristics, should be referred to specialty care.

\section{DIGITAL FEATURES}

This article is published with digital features, including a summary slide, to facilitate understanding of the article. To view digital features for this article go to https://doi.org/10.6084/ m9.figshare.13182746.

\section{INTRODUCTION}

The clinical problem of "chronic pain" has reached alarming proportions in terms of disability, consumption of health and social resources, and impact on primary and specialist care services $[1,2]$. This public health problem is considered a priority by the World Health Organization (WHO), European health

Box 1 Classification of chronic pain in version 11 of the International Classification of Diseases developed by the International Association for the Study of Pain and the World Health Organization [9]

Chronic primary pain [10]

Chronic secondary pain syndromes

- Cancer-related pain [11]

- Postsurgical/post-traumatic pain [12]

- Neuropathic pain [13]

- Secondary headache/orofacial pain [14]

- Secondary visceral pain [15]

- Secondary musculoskeletal pain [16] 
Moderate-to-severe acute pain is a risk factor for developing chronic pain [17]. Most patients with chronic pain are managed in general practice [18].

Chronic pain can have a variety of mechanisms, and can include nociceptive, neuropathic, and or nociplastic (primary) pain. Rational choice of therapy is greatly facilitated by the correct diagnosis of the type and mechanism of pain, and identification of the points where painful impulses are generated or modified, the so-called "pain generators". Comprehensive instruments are needed to accomplish this.

With reference to the IASP classification, we emphasize the difference between primary and secondary pain: the main role of a general practitioner is primarily to look after patients affected by secondary pain, since patients with primary pain are more complex and should be referred to multidisciplinary pain centers.

We propose the SIMG 3.0 approach from the Italian Society of General Medicine to decrease misdiagnosis and promote the appropriate treatment of chronic pain. The accompanying article provides an overview of pharmacological strategies based on the type of pain identified [19]. This article is based on previously conducted studies and does not contain any new studies with human participants or animals performed by any of the authors.

\section{EPIDEMIOLOGY}

Estimates of the prevalence of chronic pain among adults in the general population vary widely from 2 to $40 \%$ or more [20-22], although most studies report values between 10 and $30 \%$. The variability may be due to how chronic pain is defined and how data is collected (e.g., telephone surveys vs. observational or registry studies) [23], or to social or cultural differences among populations [24]. In 1998, the WHO reported the results of a chronic pain survey conducted in 15 primary care centers around the world [25]. The overall estimated prevalence from 5438 random interviews was $22 \%$, with wide variation between centers (range, 5.5-33.0\%). A meta-analysis focusing on 28 low- and middle-income countries reported chronic pain in $34 \%$ of adults in the general population [26]. A pooled estimate of chronic pain among adult UK residents revealed a prevalence of $43.5 \%$ (95\% CIs 38.4-48.6\%) [27]. A survey of 6000 adults in Japan revealed a chronic pain prevalence of $39.3 \%$ [28]. The US CDC estimated the prevalence of chronic pain at $20.4 \%$ among adults, based on the 2016 National Health Interview Survey [29]. In France, a mail survey with nearly 25,000 respondents revealed a chronic pain prevalence of $31.7 \%$ [30].

\section{PREVALENCE IN ITALY}

An observational study published in 2005 involving 89 Italian general practitioners (1432 contacts) found that about one-third of outpatients in general medicine reported pain, and this was chronic in about half of cases [31]. In 2006, the Italian Society of General Medicine conducted a prospective study that identified 6155 patients who visited their GPs for pain not associated with infections or migraine. The estimated prevalence of chronic pain was 3\% [32]. Results of a European study on pain in which 3849 phone calls and 300 in-depth interviews were conducted in Italy estimated the prevalence of chronic pain at $26 \%$, with more women than men being affected [33]. This result was similar to that of a cross-sectional population survey of nearly 1300 adults in Narni, Italy, which revealed a chronic pain prevalence of $28.4 \%$ [34].

\section{IMPACT OF CHRONIC PAIN ON QUALITY OF LIFE AND WORK PRODUCTIVITY}

Chronic pain significantly affects physical and psychological health, impacting both function and quality of life [35-37]. It is often associated with anxiety or depression that may complicate management or exacerbate pain perception [38]. Chronic pain is responsible for increased use of healthcare resources $[2,39,40]$ and loss of 
work productivity due to absenteeism as well as reduced function [37, 41-44].

\section{CRITICAL ISSUES REGARDING THE DIAGNOSIS AND TREATMENT OF CHRONIC PAIN IN GENERAL PRACTICE}

1. GPs do not routinely explore the different components of pain in their assessment, citing a lack of time [45].

2. A structured and coherent approach to collecting the anamnesis and evaluating symptoms and signs to identify the type and origin of the pain is lacking [45].

3. The use of non-steroidal anti-inflammatory drugs in chronic pain therapy is excessive, and often inappropriate both in terms of efficacy and the risks of side effects $[41,46]$.

4. Opioid analgesic drugs are often not used when indicated in various care settings in Italy [48].

5. There is a lack of homogeneity in the use of specialist services, both in terms of which patients to refer and when to refer them [49].

\section{DEVELOPMENT OF A DIAGNOSTIC ALGORITHM}

Identification of these problems, combined with acknowledgement that chronic pain is a major problem and an increasing burden prompted the Italian Society of General Medicine (SIMG) to involve GPs, representatives of scientific societies, institutions, and patient associations in a consensus-building process and the elaboration of a document [50]. The output includes an algorithm for structuring diagnostic and therapeutic interventions for chronic pain in general medicine. The algorithm was refined during training courses organized by SIMG, which involved approximately 180 GPs, and was subsequently assessed and revised by a multidisciplinary work group initiated by the Italian Ministry of Health [51].
The resulting chronic pain algorithm for GPs consists of a structured evaluation with clinical tests that distinguish neuropathic from nociceptive pain and, thus, mechanical structural pain from pain linked to inflammation. The goal is to identify the site of origin of the pain (the "pain generator") which, together with assessment of pain intensity, guides the most appropriate choice of therapy.

In pain literature [52], reference is made to the need to use various blocks in order to identify the origin of pain, by using two blocks with two different anesthetics (lidocaine and bupivacaine) for the duration of action, in order to reduce false positives and false negatives. It has to be said that this method replaces the use of placebo, which may raise significant ethical concerns. Two blocks with different anesthetics are considered by many clinicians (especially in the United States) to be an excessive cost for the healthcare system and, as we argue, should be used only in doubtful cases when the pain has not disappeared. Most clinicians believe that the use of lidocaine is indicative, for the duration of action of the local anesthetic, with the disappearance of both spontaneous and evoked pain. It should also be emphasized the pain relief obtained with the two different local anesthetics is perceived by the patient differently to the advantage of lidocaine. A successful result of the test is not only related to the anesthetic used but also to the active co-operation of the patient involved with it.

The algorithm identifies cases that may require referral to a pain specialist.

\section{THE PROPOSED APPROACH}

Differentiating among pain types can be difficult, but it facilitates identifying the correct therapy. A systematic approach is needed.

\section{Basic Definitions and Implications}

\section{The Somatosensory System}

Nociceptive neurons from sensory ganglia innervate somatic and visceral regions and connect to the spinal cord and brain stem, mediating sensory signal transmission from a 
first neuron in the peripheral nervous system to a second neuron in the central nervous systems. The cell body of the first neuron is in the dorsal root ganglion of the spinal nerve (or sensory cranial nerve ganglia). The cell body of the second neuron is in the spinal cord (or brainstem) and decussates to the contralateral side in the spinal cord (or brainstem). These constitute the ascending pathway that initiates the awareness of pain. A second, descending pathway modulates pain perception by modifying conditions at the synapse between the first and second neurons of the ascending pathway. Spinal sensitization occurs when ascending impulses are amplified.

\section{Pain Types}

Nociceptive pain is the most common type. It plays a key role in sending warning signals to protect the body from (further) injury in response to noxious chemical, thermal, or mechanical stress. Pain receptors for these noxious stimuli have relatively high thresholds [54], compared for example to tactile receptors. Myelinated A-delta peripheral nerve fibers are involved in the rapid transmission of shortlived signal to the dorsal horn of the spinal cord, which then relays the signal to the central nervous system. Unmyelinated $\mathrm{C}$ peripheral nerve fibers transmit slow, long-lived impulses, for example nociceptive pain signals triggered by inflammatory mediators like histamine.

Box 2 Pain terminology from the International Association for the Study of Pain [53]

Nociceptive pain-Pain that arises from actual or threatened damage to non-neural tissue and is due to the activation of nociceptors.

Neuropathic pain-Pain caused by a lesion or disease of the somatosensory nervous system.

Nociplastic pain-Pain that arises from altered nociception despite no clear evidence of actual or threatened tissue damage causing the activation of peripheral nociceptors or evidence for disease or lesion of the somatosensory system causing the pain.
Nociceptive pain can be further divided into somatic and visceral pain. Somatic pain is superficial or deep pain that originates in peripheral tissues (e.g., skin, muscle, bone). Visceral pain originates within the abdomen or specific organs (Box 2).

Neuropathic pain is a second general type of pain that arises "as a direct consequence of a lesion or disease affecting the somatosensory system", [55]. Impulses are generated from ectopic sites due to damage or dysfunction of the peripheral nervous system (peripheral neuropathic pain) or central nervous system (central neuropathic pain) [55]. These ectopic impulses generate the sensation of pain in the innervated area (positive symptoms), while the nerve damage causes sensory deficits in the innervated area (negative symptoms). The location of these symptoms should be consistent with a neurological pattern. Depending on the cause, neuropathic pain can be generalized or localized [56]. The most relevant causes of peripheral neuropathic pain (PNP) include painful diabetic peripheral neuropathy (PDPN), postherpetic neuralgia (PHN), HIV-associated neuropathy (HIV-AN), and chemotherapy-induced peripheral neuropathy.

Neuropathic pain represents a significant burden for patients, society, and healthcare systems [57] that is associated with more severe pain, higher workplace absenteeism, and higher medical costs compared to chronic non-neuropathic pain [58]. It requires a different therapeutic approach from nociceptive pain and can be challenging to treat $[59,60]$.

A study conducted with 113 general practitioners in Italy who saw 58,480 adults over a 3 -month period revealed a prevalence of chronic peripheral neuropathic pain of $0.77 \%$ [61]. Diabetic neuropathy and postherpetic pain were the two most common types $(0.31$ and $0.24 \%$, respectively). Studies in the United Kingdom and France have estimated that among patients in the general population with chronic pain, $6-8 \%$ have neuropathic pain $[30,62]$; whereas about half of the patients attending pain clinics have neuropathic pain. A systematic review of epidemiological studies of neuropathic pain in the general population revealed an estimated prevalence between 7 and 
$10 \%$ [63]. This is projected to increase due to population aging, rising obesity, and longer cancer survival with chemotherapy that may have neuropathic pain as a side effect [64].

A third pain type, called nociplastic pain, is defined by the IASP as "pain that arises from altered nociception despite no clear evidence of actual or threatened tissue damage causing the activation of peripheral nociceptors or evidence for disease or lesion of the somatosensory system causing the pain" [53]. It can be considered a form of primary pain, which is defined as pain in one or more anatomical regions that (1) "persists or recurs for longer than 3 months", (2) "is associated with significant emotional distress", and (3) has symptoms that "are not better accounted for by another diagnosis" [10]. Whereas chronic secondary pain can be considered a symptom of another condition, in chronic primary pain, the pain itself may be considered a disease. Some of the conditions in this classification include chronic widespread pain such as fibromyalgia and complex regional pain syndromes, irritable bowel syndrome, and chronic nonspecific low back pain. These conditions often involve central sensitization [65] and may be associated with psychological distress, fear-avoidance, and pain catastrophizing. Patients may benefit from suitable cognitive and behavioral strategies.

The Central Sensitisation Inventory may be useful for identifying patients with key symptoms associated with this con [66]. It may be difficult to distinguish fibromyalgia from other conditions that cause chronic widespread pain [67]. In addition to quantifying the number of painful sites, an instrument like the FibroDetect $^{\circledR}$ questionnaire for fibromyalgia can be useful for supporting diagnosis [68].

\section{Differentiating Nociceptive and Neuropathic Pain}

Screening tools (reviewed in [69]) include the Brief Pain Inventory (BPI) [70], the PainDETECT score [71], the LANSS [72] or the DN4 [73]. The LANSS and DN4 may be more specific because, in addition to the questionnaire, they include a rudimentary clinical assessment [74]. It is

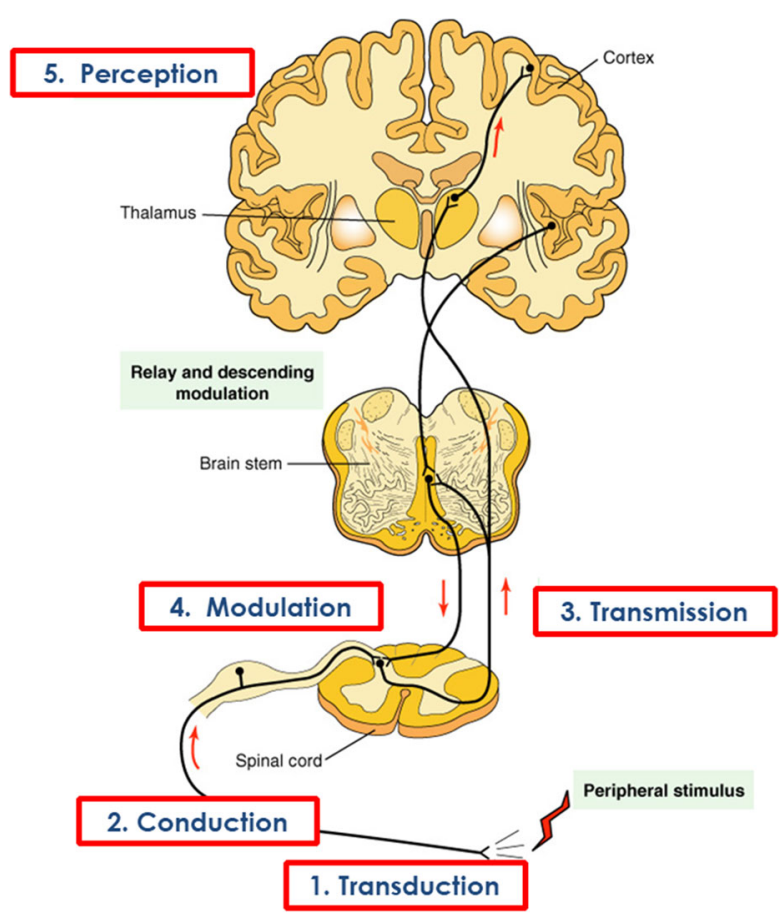

Fig. 1 Nerve impulse transduction, conduction, transmission, modulation, and perception. Modified with permission from Basic Neurochemistry. Molecular, Cellular and Medical Aspects. Edited by GJ Siegel, RW. Albers, ST Brady, DL Price. Chapter 57 Pain, M. Costigan et al. pp 927-937. VII Eds Elsevier [ Copyright 2006. American Society for Neurochemistry]

important to note that while these tools are useful for screening purposes, they cannot replace a thorough clinical assessment [75]. A careful history, evaluation of the pain quality, and a neurological examination to assess sensory function can provide important clues to the type of pain. Careful delineation of the painful area and any sensory abnormalities permits identification of specific peripheral nerve or nerve root involvement (Fig. 1).

Mixed pain can occur in cancer patients when neoplastic growth causes damage to both somatic tissue and nerve tissue [76]. Although not clearly defined in guidelines (reviewed in [77]), mixed nociceptive-neuropathic pain can occur also in low back pain with radicular pain. In this case, inflammation from tissue damage causes and sustains the neuropathic pain [78]. Essentially, there is a partial nerve fiber lesion, such that ectopic discharges are stimulated by 


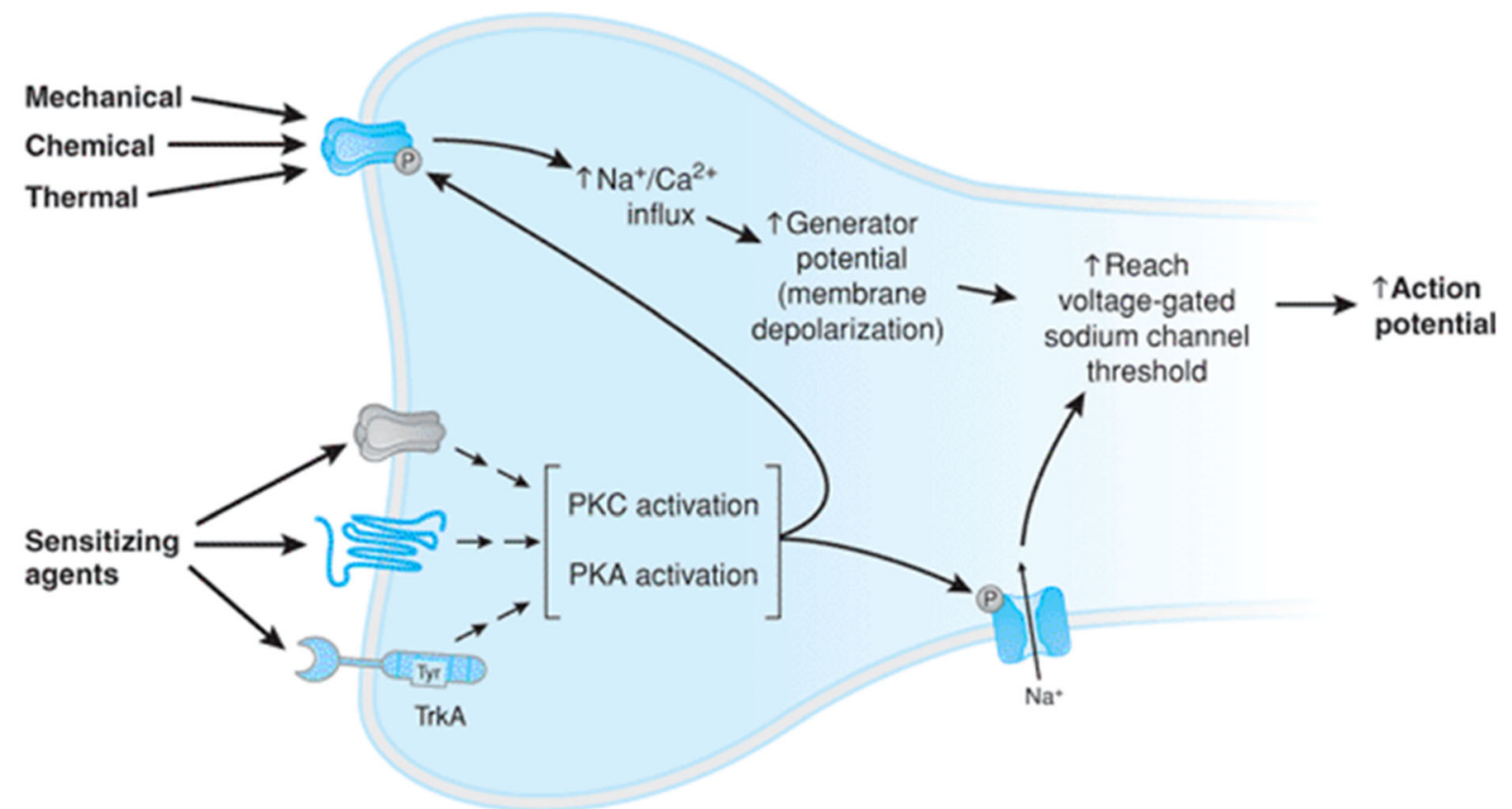

Fig. 2 Sensitizing agents lower the threshold for pain receptors. Reproduced with permission from Golan, David E., Armen H. Tashjian, and Ehrin J. Armstrong, eds.

mechanical or inflammatory stimuli, but the lesion is not severe enough to produce a conduction deficit. The resulting pain will be sensed in areas compatible with innervation. Chronic lower back pain may also be primary musculoskeletal pain, especially if accompanied by significant psychosocial contributors.

Activation of pain signaling in response to a painful stimulus is not static. The pain threshold, or sensitivity, can be modulated by a large variety of sensitizing agents (e.g., prostaglandins, inflammatory cytokines, etc.) (Fig. 2).

Hyperalgesia occurs when nociceptors detect a noxious stimulus as more painful than expected. Allodynia occurs when a completely non-noxious stimulus (e.g., light touch) causes pain. Allodynia can also result from damaged nociceptors on peripheral nerves. Hyperalgesia and allodynia may be associated with either nociceptive or neuropathic pain, although the underlying mechanisms are different. In the case of nociceptive pain, allodynia is mainly the result of peripheral sensitization and is often called primary allodynia to underscore the fact that it identifies the pain generator. Sometimes the area of allodynia extends beyond the pain
Principles of pharmacology: the pathophysiologic basis of drug therapy. Lippincott Williams \& Wilkins, 2011

generator. This phenomenon is due to central sensitization that causes an enlargement of the receptor fields in the spinal cord and is called secondary allodynia.

In neuropathic pain, allodynia, which is often called mechanical or dynamic allodynia, is due to more complex mechanisms that involve modification of the electrical activity at the ectopic site on damaged fibers, combined with central sensitization. In central sensitization due to peripheral neuropathic pain, there is extensive participation of wide dynamic range (WDR) neurons that connect tactile fiber activity with the nociceptive pathways.

Referred pain is perceived in a location other than where it originates. Figure 3 schematically illustrates the possible patterns of referred pain (consult anatomical maps for more detailed information). The pain is always referred to a site outside the territory of innervation of the responsible structure, but generally in the same spinal segment (convergence; e.g., the arm in angina, the shoulder in biliary colic) or when two organs share overlapping peripheral innervation (dichotomy; e.g., colon and bladder). 


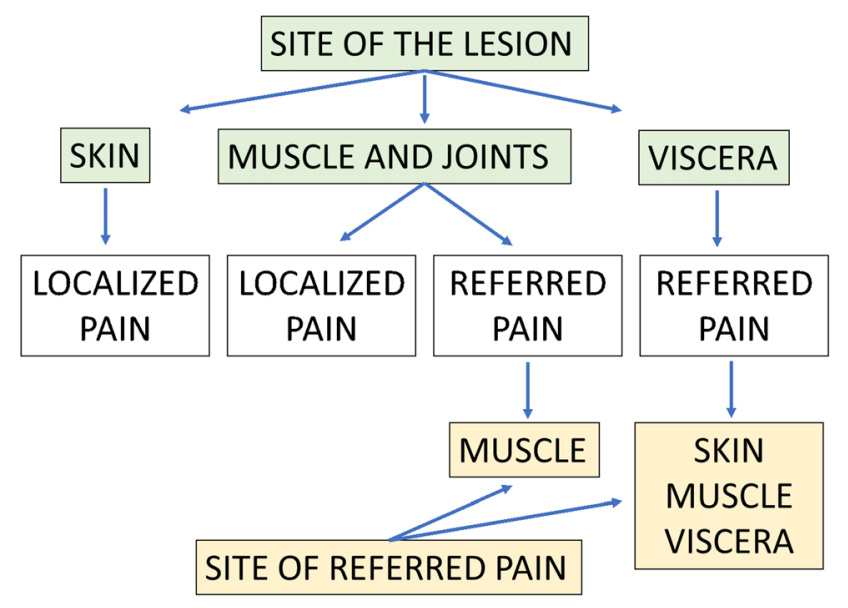

Fig. 3 Referred pain patterns

Visceral pain may be referred to specific superficial sites.

Referred pain should not be confused with secondary allodynia, in which spinal sensitization enlarges the area where pain is perceived and where pain can be elicited with normally painless stimuli.

\section{DIAGNOSTIC WORKUP USING THE SIMG METHOD VERSION 3.0}

The diagnosis is made by combining the information reviewed in the previous sections with the results from the six observations/tests below, which can be performed in the office using the simple tools shown in Fig. 4.

\section{Diagnostic Workup}

From the patient's medical history, determine whether they have a neurological condition that is associated with nerve fiber lesions, such as multiple sclerosis or herpes zoster infection.

1. The first step is to delineate the affected area with a whiteboard marking pen to outline the confines of the area in which pain or

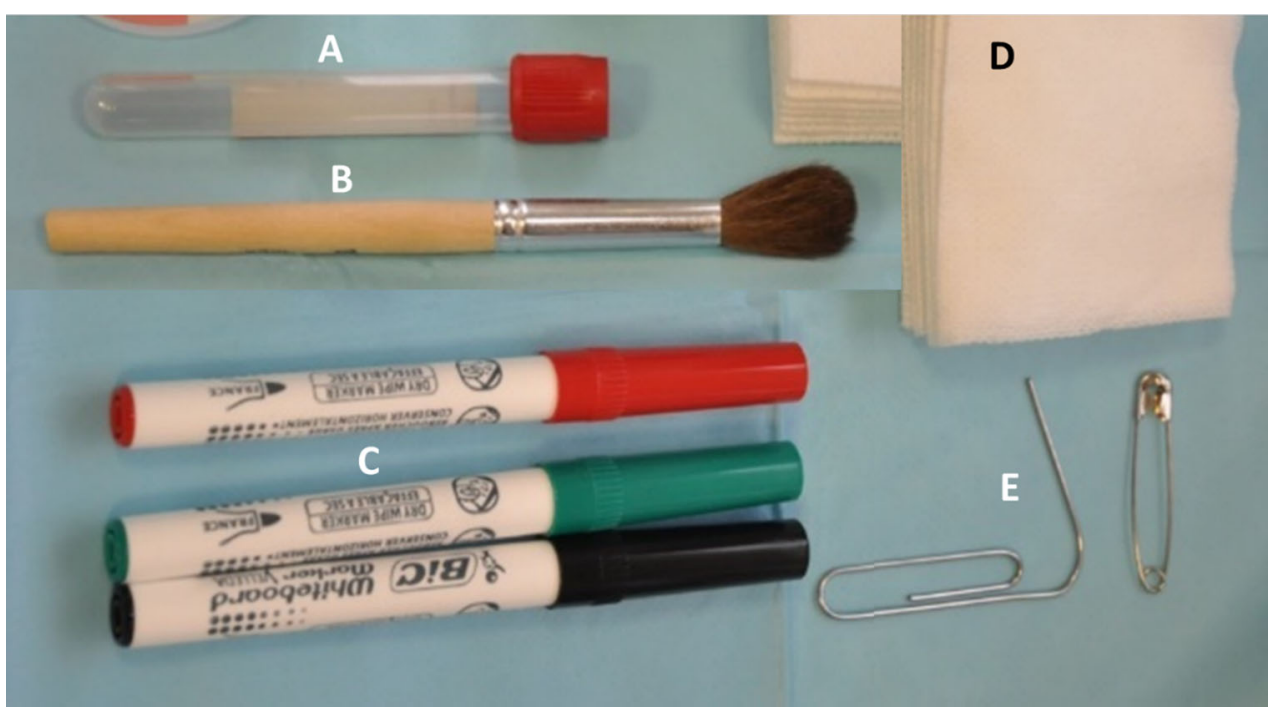

Fig. 4 Simple instruments for conducting the pain assessment. a A tube of warm water $\left(40^{\circ} \mathrm{C}\right), \mathbf{b}$ a soft-bristle brush, $\mathbf{c}$ whiteboard markers I 3 colors, $\mathbf{d}$ soft cotton or gauze, $\mathbf{e}$ sharp objects such as a paperclip or pin 


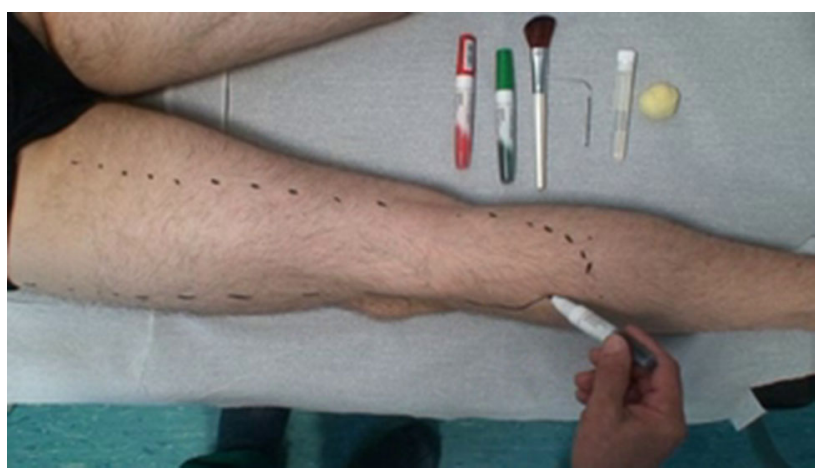

Fig. 5 Topographic definition of the symptomatic area

discomfort is provoked by light touch. Once this area is circumscribed, we use the red pen to identify the zone(s) of major pain within this area (Fig. 5).

2. Are there particular elements in the painful area (e.g., corresponding to a plexus, root or nerve)?

3. Are there any signs of somatosensory system deficiency?

Three stimuli are used to test for sensitivity to light touch discrimination (cotton ball or gauze), pinprick (paperclip/pin) and temperature (tube of water at $40^{\circ} \mathrm{C}$ ) (Fig. 6). Explain the procedure to the patient, including the purpose of the assessment: "I will now test the sensibility inside the area and compare it to outside of the area. When I ask whether you feel the stimulus, please respond yes or no". Touch lightly with the cotton ball inside the area and compare to outside (contralateral location), asking for a response at each touch. Repeat this procedure with a gentle poke using an opened paperclip and then again with the tube of warm water. From this assessment, we can determine whether the patient has partial or total sensory deficits indicative of neuropathic pain (Fig. 6). Assessment of sensation within the affected area and comparison with surrounding unaffected area.

4. Are there any signs of receptor sensitization (primary allodynia)?

The next step involves searching for primary allodynia by determining whether a normally painless contact (light brushing, gentle pressing with finger) within the area causes discomfort or pain.

5. Are there any signs of spinal sensitization (secondary allodynia)?

This is tested by applying gentle strokes with a soft bristle brush in and adjacent to the pain area. If secondary allodynia is

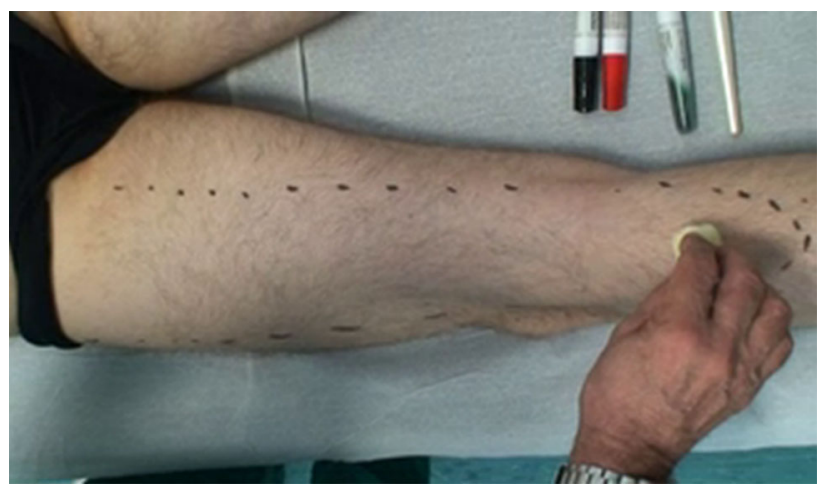

Fig. 6 Assessment with a cotton swab of tactile sensitivity in the pain area declared by the patient 


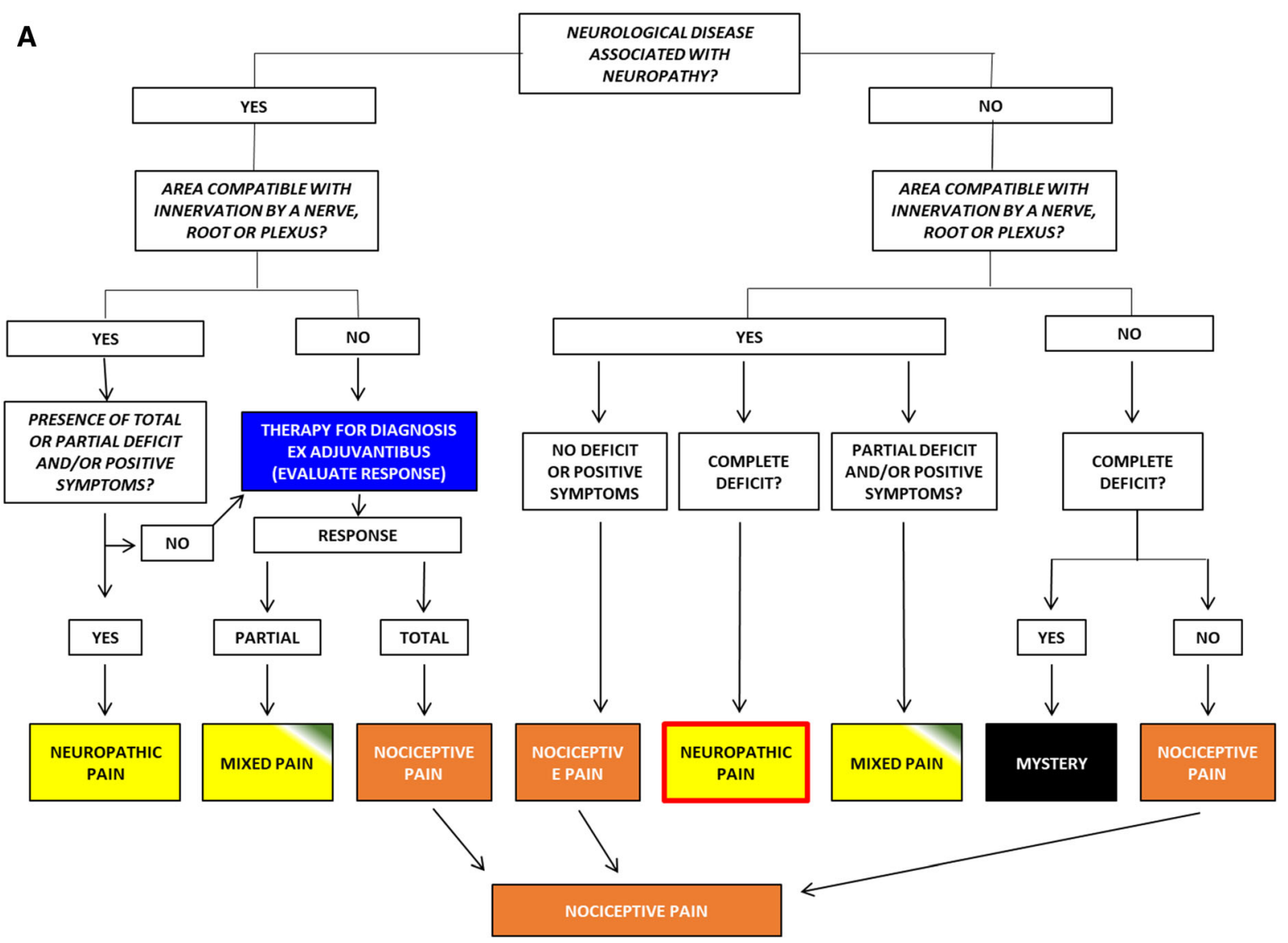

Fig. 7 Part A: Diagnostic algorithm. Part B: Diagnosis of nociceptive pain

present, brushing will provoke discomfort or pain. Indicate any zones of secondary allodynia on the patient with a different color marker.

6. Are there inconsistencies?

Armed with the results of these simple inquiries and a thorough anamnesis with assessment of psychological stress, the type of pain can be identified using the algorithm (Fig. 7).

\section{CASES TO ILLUSTRATE THE ALGORITHM}

\section{Case 1}

A young patient with loss of tactile, thermal and pain sensation in the 2 nd, 3rd finger of the right hand in the distal part (last phalanx), also feeling pain in the cervical spine.

An initial hypothesis suggested cervical root pain. However, the extent of the peripheral signs did not support this view. A further diagnostic intervention revealed that the patient held incandescent objects in their line of work and the protective gloves being worn were damaged at the level of the aforementioned fingers. An MRI of the cervical spine revealed pain in the C3-C4 zygapophyseal joints.

\section{Case 2}

A senior patient with deep pain in specific areas of the leg and the calf of the right lower limb, experiencing tingling in the ankle and outer section of the foot. 


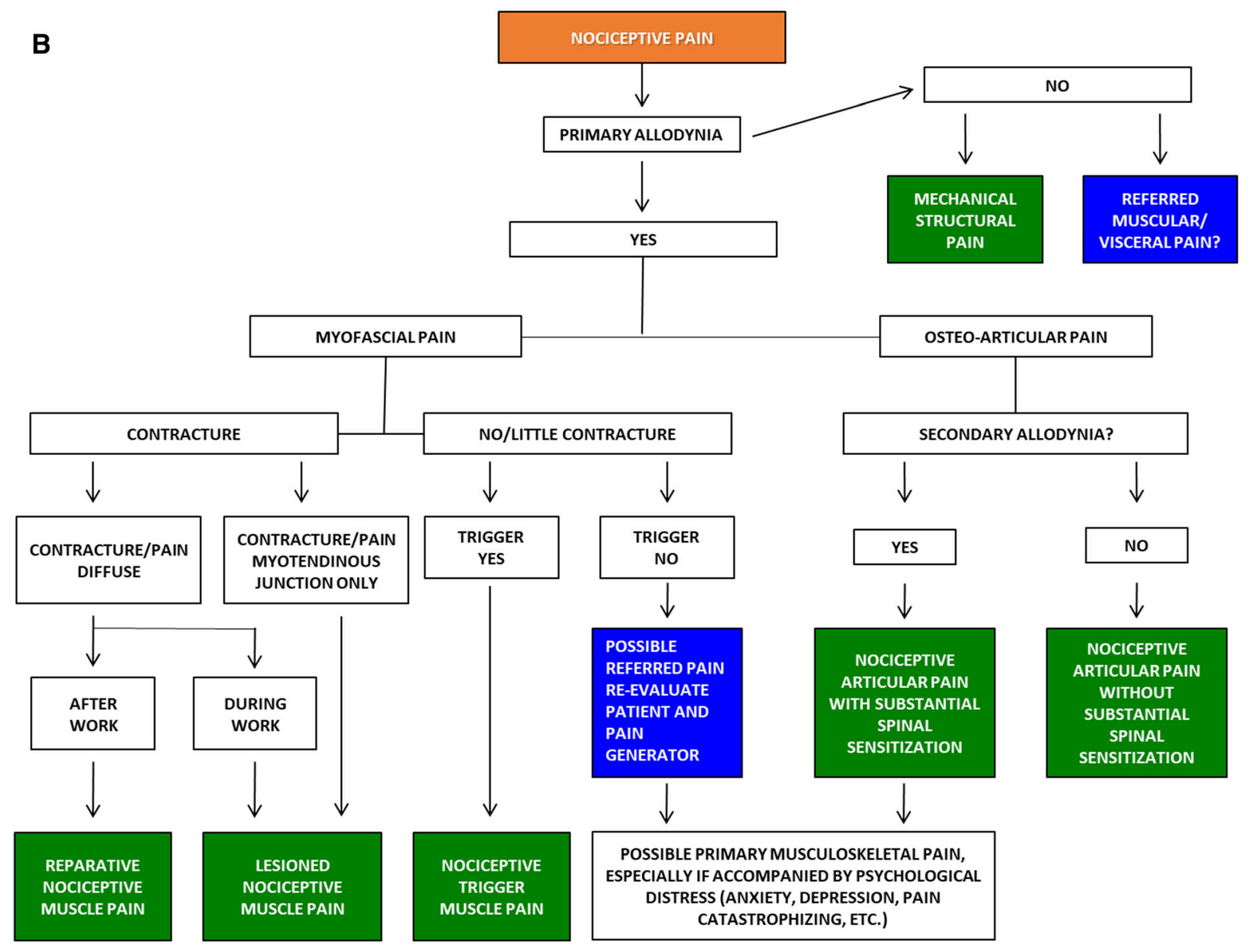

Fig. 7 continued

A clinical assessment revealed signs of tactile sensitivity deficit and stinging in the area in which the patient felt tingling (that is in the dermatome of the 5th lumbar root). A further MRI check revealed an intraforaminal disc herniation (right-sided). A sensitivity assessment can prove to be essential, while pain distribution is only indicative. It is always necessary to consider that for each spinal root there is a dermatome in which superficial sensitivities should be evaluated and a different territory of deep pain.

\section{CONCLUSIONS}

This algorithm, developed by the Italian Society of General Medicine (SIMG), is currently offered as a part of Continuing Medical Education for GPs in Italy. The goal is to provide primary care physicians with the diagnostic skills needed to manage patients presenting in general practice with chronic pain or refer them to specialty care when appropriate. The accompanying article in this issue provides information and rationale to support treatment decisions based on type of pain and patient characteristics identified here.

\section{ACKNOWLEDGEMENTS}

Funding. Sponsorship for the Rapid Service Fee was funded by Alfasigma, Italy.

Editorial Assistance. Editorial assistance in the preparation of this article was provided by Richard Vernell, an independent medical writer, on behalf of Springer Healthcare, Italy. This support was funded by Alfasigma, Italy. 
Authorship. All named authors meet the International Committee of Medical Journal Editors (ICMJE) criteria for authorship for this article, take responsibility for the integrity of the work as a whole, and have given their approval for this version to be published.

Disclosures. Diego Fornasari declared relationships during the past 2 years as conference speaker, member of advisory boards or consultants for the following companies: Abiogen, Alfasigma, Astellas, Bayer, Grünenthal, Indena, Molteni, Scharper, SPA, Zambon. Alberto Magni declares relationships with Angelini, Alfasigma, Ibsa Farmaceutici, Grünenthal, and Pfizer. Cesare Bonezzi, Claudio Cricelli, and Giuseppe Ventriglia have nothing to disclose.

Compliance with Ethics Guidelines. This article is based on previously conducted studies and does not contain any new studies with human participants or animals performed by any of the authors.

Open Access. This article is licensed under a Creative Commons Attribution-NonCommercial 4.0 International License, which permits any non-commercial use, sharing, adaptation, distribution and reproduction in any medium or format, as long as you give appropriate credit to the original author(s) and the source, provide a link to the Creative Commons licence, and indicate if changes were made. The images or other third party material in this article are included in the article's Creative Commons licence, unless indicated otherwise in a credit line to the material. If material is not included in the article's Creative Commons licence and your intended use is not permitted by statutory regulation or exceeds the permitted use, you will need to obtain permission directly from the copyright holder. To view a copy of this licence, visit http://creativecommons.org/licenses/by$\mathrm{nc} / 4.0 /$.

\section{REFERENCES}

1. Romanelli RJ, Shah SN, Ikeda L, et al. Patient characteristics and healthcare utilization of a chronic pain population within an integrated healthcare system. Am J Manag Care. 2017;23(2): e50-6.

2. Hansen AB, Skurtveit S, Borchgrevink PC, et al. Consumption of and satisfaction with health care among opioid users with chronic non-malignant pain. Acta Anaesthesiol Scand. 2015;59(10): 1355-66.

3. Roy É, Côté RJ, Hamel D, et al. Opioid prescribing practices and training needs of Québec family physicians for chronic noncancer pain. Pain Res Manag. 2017;2017:1365910.

4. O'Rorke JE, Chen I, Genao I, Panda M, Cykert S. Physicians' comfort in caring for patients with chronic nonmalignant pain. Am J Med Sci. 2007;333(2):93-100.

5. Harris JM Jr, Elliott TE, Davis BE, Chabal C, Fulginiti JV, Fine PG. Educating generalist physicians about chronic pain: live experts and online education can provide durable benefits. Pain Med. 2008;9(5): 555-63.

6. Chelimsky TC, Fischer RL, Levin JB, Cheren MI, Marsh SK, Janata JW. The primary practice physician program for chronic pain (@) 4PCP): outcomes of a primary physician-pain specialist collaboration for community-based training and support. Clin J Pain. 2013;29(12):1036-43.

7. Raja SN, Carr DB, Cohen M, Finnerup NB, Flor H, Gibson S, et al. The revised International Association for the Study of Pain definition of pain: concepts, challenges, and compromises. Pain United States. 2020. https://doi.org/10.1097/j.pain. 0000000000001939 .

8. Treede R-D, Rief W, Barke A, Aziz Q, Bennett MI, Benoliel R, et al. A classification of chronic pain for ICD-11. Pain. 2015;156:1003-7.

9. Treede R-D, Rief W, Barke A, Aziz Q, Bennett MI, Benoliel R, et al. Chronic pain as a symptom or a disease: the IASP Classification of Chronic Pain for the International Classification of Diseases (ICD11). Pain United States. 2019;160:19-27.

10. Nicholas M, Vlaeyen JWS, Rief W, Barke A, Aziz Q, Benoliel R, et al. The IASP classification of chronic pain for ICD-11: chronic primary pain. Pain United States. 2019;160:28-37.

11. Bennett MI, Kaasa S, Barke A, Korwisi B, Rief W, Treede R-D. The IASP classification of chronic pain 
for ICD-11: chronic cancer-related pain. Pain United States. 2019;160:38-44.

12. Schug SA, Lavandhomme P, Barke A, Korwisi B, Rief W, Treede R-D. The IASP classification of chronic pain for ICD-11: chronic postsurgical or posttraumatic pain. Pain United States. 2019;160:45-52.

13. Scholz J, Finnerup NB, Attal N, Aziz Q, Baron R, Bennett MI, et al. The IASP classification of chronic pain for ICD-11: chronic neuropathic pain. Pain. 2019;160:53-9.

14. Benoliel R, Svensson P, Evers S, Wang S-J, Barke A, Korwisi B, et al. The IASP classification of chronic pain for ICD-11: chronic secondary headache or orofacial pain. Pain United States. 2019;160:60-8.

15. Aziz Q, Giamberardino MA, Barke A, Korwisi B, Baranowski AP, Wesselmann $\mathrm{U}$, et al. The IASP classification of chronic pain for ICD-11: chronic secondary visceral pain. Pain United States. 2019;160:69-76.

16. Perrot S, Cohen M, Barke A, Korwisi B, Rief W, Treede R-D. The IASP classification of chronic pain for ICD-11: chronic secondary musculoskeletal pain. Pain United States. 2019;160:77-82.

17. Rosenbloom BN, Khan S, McCartney C, Katz J. Systematic review of persistent pain and psychological outcomes following traumatic musculoskeletal injury. J Pain Res. 2013;6:39-51.

18. Klinar I, Ferhatovic L, Banozic A, et al. Physicians' attitudes about interprofessional treatment of chronic pain: family physicians are considered the most important collaborators. Scand J Caring Sci. 2013;27(2):303-10.

19. Bonezzi C, Fornasari D, Cricelli C, Magni A, Ventriglia G. Pharmacological management of adults with chronic non-cancer pain in general practice. Pain Ther. 2020. https://doi.org/10.1007/s40122020-00218-9.

20. Verhaak PF, Kerssens JJ, Dekker J, Sorbi MJ, Bensing JM. Prevalence of chronic benign pain disorder among adults: a review of the literature. Pain. 1998;77(3):231-9.

21. Blyth FM, March LM, Brnabic AJ, Jorm LR, Williamson M, Cousins MJ. Chronic pain in Australia: a prevalence study. Pain. 2001;89(2-3):127-34.

22. Reid KJ, Harker J, Bala MM, Truyers C, Kellen E, Bekkering GE, Kleijnen J. Epidemiology of chronic non-cancer pain in Europe: narrative review of prevalence, pain treatments and pain impact. Curr Med Res Opin. 2011;27(2):449-62.
23. Steingrímsdóttir ÓA, Landmark T, Macfarlane GJ, Nielsen CS. Defining chronic pain in epidemiological studies: a systematic review and meta-analysis. Pain. 2017;158(11):2092-107.

24. Rahim-Williams B, Riley JL 3rd, Williams AK, Fillingim RB. A quantitative review of ethnic group differences in experimental pain response: do biology, psychology, and culture matter? Pain Med. 2012;13(4):522-40.

25. Gureje O, Von Korff M, Simon GE, Gater R. Persistent pain and well-being: a World Health Organization Study in Primary Care. JAMA. 1998;280(2): 147-51.

26. Jackson T, Thomas S, Stabile V, Shotwell M, Han X, McQueen K. A systematic review and meta-analysis of the global burden of chronic pain without clear etiology in low- and middle-income countries: trends in heterogeneous data and a proposal for new assessment methods. Anesth Analg. 2016;123(3):739-48.

27. Fayaz A, Croft P, Langford RM, Donaldson LJ, Jones GT. Prevalence of chronic pain in the UK: a systematic review and meta-analysis of population studies. BMJ Open. 2016;6(6):e010364.

28. Inoue S, Kobayashi F, Nishihara $\mathrm{M}$, et al. Chronic pain in the Japanese community-prevalence, characteristics and impact on quality of life. PLoS One. 2015;10(6):e0129262.

29. Dahlhamer J, Lucas J, Zelaya C, et al. Prevalence of chronic pain and high-impact chronic pain among adults-United States, 2016. MMWR Morb Mortal Wkly Rep. 2018;67(36):1001-6.

30. Bouhassira D, Lanteri-Minet M, Attal N, Laurent B, Touboul C. Prevalence of chronic pain with neuropathic characteristics in the general population. Pain. 2008;136(3):380-7.

31. Koleva D, Krulichova I, Bertolini G, Caimi V, Garattini L. Pain in primary care: an Italian survey. Eur J Public Health. 2005;15(5):475-9.

32. Piccoliori G, Pavone P, Turbil E, et al. Italian pain Research: [Preliminary data from an observational study in General Medicine]. 23rd National Congress of the Italian Society of General Medicine (SIMG). Florence, November 23-25. 2006. [Italian]

33. Breivik H, Collett B, Ventafridda V, Cohen R, Gallacher D. Survey of chronic pain in Europe: prevalence, impact on daily life, and treatment. Eur J Pain. 2006;10(4):287-333.

34. Del Giorno R, Frumento P, Varrassi G, Paladini A, Coaccioli S. Assessment of chronic pain and access 
to pain therapy: a cross-sectional population-based study. J Pain Res. 2017;10:2577-84.

35. Alonso J, Ferrer M, Gandek B, IQOLA Project Group, et al. Health-related quality of life associated with chronic conditions in eight countries: results from the International Quality of Life Assessment (IQOLA) Project. Qual Life Res. 2004;13(2):283-98.

36. Bernfort L, Gerdle B, Rahmqvist M, Husberg M, Levin LA. Severity of chronic pain in an elderly population in Sweden-impact on costs and quality of life. Pain. 2015;156(3):521-7.

37. Kawai K, Kawai AT, Wollan P, Yawn BP. Adverse impacts of chronic pain on health-related quality of life, work productivity, depression and anxiety in a community-based study. Fam Pract. 2017;34(6): 656-61.

38. Kroenke K, Outcalt S, Krebs E, et al. Association between anxiety, health-related quality of life and functional impairment in primary care patients with chronic pain. Gen Hosp Psychiatry. 2013;35(4):359-65.

39. Blyth FM, March LM, Brnabic AJ, Cousins MJ. Chronic pain and frequent use of health care. Pain. 2004;111(1-2):51-8.

40. Eriksen J, Sjøgren P, Ekholm O, Rasmussen NK. Health care utilisation among individuals reporting long-term pain: an epidemiological study based on Danish National Health Surveys. Eur J Pain. 2004;8(6):517-23.

41. van Leeuwen MT, Blyth FM, March LM, Nicholas MK, Cousins MJ. Chronic pain and reduced work effectiveness: the hidden cost to Australian employers. Eur J Pain. 2006;10(2):161-6.

42. McDonald M, DiBonaventura M, Ullman S. Musculoskeletal pain in the workforce: the effects of back, arthritis, and fibromyalgia pain on quality of life and work productivity. J Occup Environ Med. 2011;53(7):765-70.

43. Gaskin DJ, Richard P. The economic costs of pain in the United States. J Pain. 2012;13(8):715-24.

44. Henschke N, Kamper SJ, Maher CG. The epidemiology and economic consequences of pain. Mayo Clin Proc. 2015;90(1):139-47.

45. Piccoliori G, Engl A, Gatterer D, Sessa E, der Schmitten J, Abholz HH. Management of low back pain in general practice-is it of acceptable quality: an observational study among 25 general practices in South Tyrol (Italy). BMC Fam Pract. 2013;14:148.
46. Payne R. Limitations of NSAIDs for pain management: toxicity or lack of efficacy? J Pain. 2000;1(3 Suppl):14-8.

47. Jalan R, Williams R, Bernuau J. Paracetamol: are therapeutic doses entirely safe? Lancet. 2006;368: 2195-6.

48. Apolone G, Corli O, Caraceni A, et al. Pattern and quality of care of cancer pain management. Results from the Cancer Pain Outcome Research Study Group. Br J Cancer. 2009;100(10):1566-74.

49. Andersson HI, Ejlertsson G, Leden I, Rosenberg C. Chronic pain in a geographically defined general population: studies of differences in age, gender, social class, and pain localization. Clin J Pain. 1993;9(3):174-82.

50. Lora Aprile P, Cancian M, Apolone G, Bonezzi C. Società Italiana di Medicina Generale. Documento di indirizzo SIMG sull'assistenza al paziente con dolore cronico non oncologico in Medicina Generale [Italian]. https://www.simg.it/documenti/ aree_cliniche/Osteoarticolare/DCNO-definitivo. pdf.

51. Italian Health Ministry. Il dolore cronico in Medicina Generale. 2013 [Italian]. https://www. salute.gov.it/imgs/C_17_pubblicazioni_2076_ allegato.pdf.

52. DePalma MJ, Ketchum JM, Saullo T. What is the source of chronic low back pain and does age play a role? Pain Med. 2011;12:224-33.

53. International Association for the study of Pain. IASP Terminology-IASP [Internet]. https://www.iasppain.org/terminology?. Accessed 4 Oct 2020.

54. Mickle AD, Shepherd AJ, Mohapatra DP. Sensory TRP channels: the key transducers of nociception and pain. Prog Mol Biol Transl Sci. 2015;131: 73-118.

55. Treede RD, Jensen TS, Campbell JN, et al. Neuropathic pain: redefinition and a grading system for clinical and research purposes. Neurology. 2008;70(18):1630-5.

56. Mick G, Baron R, Finnerup NB, Hans G, Kern KU, Brett B, Dworkin RH. What is localized neuropathic pain? A first proposal to characterize and define a widely used term. Pain Manag. 2012;2(1):71-7.

57. Smith BH, Torrance N. Epidemiology of neuropathic pain and its impact on quality of life. Curr Pain Headache Rep. 2012;16(3):191-8.

58. Langley PC, Van Litsenburg C, Cappelleri JC, Carroll $\mathrm{D}$. The burden associated with neuropathic 
pain in Western Europe. J Med Econ. 2013;16(1): 85-95.

59. Finnerup NB, Attal N, Haroutounian S, et al. Pharmacotherapy for neuropathic pain in adults: a systematic review and meta-analysis. Lancet Neurol. 2015;14(2):162-73.

60. Baron R, Maier C, Attal N, et al. Peripheral neuropathic pain: a mechanism-related organizing principle based on sensory profiles. Pain. 2017;158(2): 261-72.

61. Buono N, Thulesius H, Petrazzuoli F, Castelli E, Cambielli M. Postherpetic neuralgia, diabetic neuropathy, and trigeminal neuralgia-chronic peripheral neuropathic pain in 58,480 rural Italian primary care patients. J Family Med Prim Care. 2017;6(1):110-4.

62. Torrance N, Smith BH, Bennett MI, Lee AJ. The epidemiology of chronic pain of predominantly neuropathic origin. Results from a general population survey. J Pain. 2006;7(4):281-9.

63. van Hecke O, Austin SK, Khan RA, Smith BH, Torrance N. Neuropathic pain in the general population: a systematic review of epidemiological studies. Pain. 2014;155(4):654-62.

64. Moulin D, Boulanger A, Clark AJ, Canadian Pain Society, et al. Pharmacological management of chronic neuropathic pain: revised consensus statement from the Canadian Pain Society. Pain Res Manag. 2014;19(6):328-35.

65. Woolf CJ. Central sensitization: implications for the diagnosis and treatment of pain. Pain. 2011;152:S2-15.

66. Mayer TG, Neblett R, Cohen H, Howard KJ, Choi $\mathrm{YH}$, Williams MJ, et al. The development and psychometric validation of the central sensitization inventory. Pain Pract. 2012;12:276-85.

67. Häuser W, Perrot S, Sommer C, Shir Y, Fitzcharles M-A. Diagnostic confounders of chronic widespread pain: not always fibromyalgia. Pain Rep. 2017;2: e598.

68. Baron R, Perrot S, Guillemin I, Alegre C, Dias-Barbosa $\mathrm{C}$, Choy $\mathrm{E}$, et al. Improving the primary care physicians' decision making for fibromyalgia in clinical practice: development and validation of the Fibromyalgia Detection (FibroDetect ${ }^{\circledR}$ ) screening tool. Health Qual Life Outcomes. 2014;12:128.
69. Bouhassira D, Attal N. Diagnosis and assessment of neuropathic pain: the saga of clinical tools. Pain. 2011;152(3 Suppl):S74-83.

70. Erdemoglu AK, Koc R. Brief Pain Inventory score identifying and discriminating neuropathic and nociceptive pain. Acta Neurol Scand. 2013;128(5): 351-8.

71. Cappelleri JC, Koduru V, Bienen EJ, Sadosky A. Characterizing neuropathic pain profiles: enriching interpretation of painDETECT. Patient Relat Outcome Meas. 2016;7:93-9.

72. Bennett MI, Smith BH, Torrance N, Potter J. The S-LANSS score for identifying pain of predominantly neuropathic origin: validation for use in clinical and postal research. J Pain. 2005;6(3): 149-58.

73. Bouhassira D, Attal N, Alchaar H, et al. Comparison of pain syndromes associated with nervous or somatic lesions and development of a new neuropathic pain diagnostic questionnaire (DN4). Pain. 2005;114(1-2):29-36.

74. Canadian Agency for Drugs and Technologies in Health. Diagnostic methods for neuropathic pain: a review of diagnostic accuracy [Internet]. Ottawa, Ontario; 2015. Conclusions and implications for decision or policy making. https://www.ncbi.nlm. nih.gov/books/NBK304866/.

75. Mathieson S, Maher CG, Terwee CB, Folly de Campos T, Lin CW. Neuropathic pain screening questionnaires have limited measurement properties. A systematic review. J Clin Epidemiol. 2015;68(8):957-66.

76. Davis MP. Cancer-related neuropathic pain: review and selective topics. Hematol Oncol Clin N Am. 2018;32(3):417-31.

77. Freynhagen R, Arevalo Parada H, Calderon-Ospina $\mathrm{CA}$, et al. Current understanding of the mixed pain concept: a brief narrative review. Curr Med Res Opin. 2018;27:1-16.

78. Nijs J, Apeldoorn A, Hallegraeff H, et al. Low back pain: guidelines for the clinical classification of predominant neuropathic, nociceptive, or central sensitization pain. Pain Physician. 2015;18(3): E333-46. 